\title{
Commitment to Environmental and Climate Change Sustainability under Competition
}

\author{
Jeong Eun Sim ${ }^{1}$ and Bosung Kim ${ }^{2, *}$ \\ 1 School of Business, University of British Columbia, Vancouver, BC V6T 1Z2, Canada; \\ jeongeun.sim@gmail.com \\ 2 Department of Industrial Engineering, Pusan National University, Busan 46241, Korea \\ * Correspondence: bosung.kim@pusan.ac.kr; Tel.: +82-51-510-3355
}

Received: 4 March 2019; Accepted: 1 April 2019; Published: 8 April 2019

check for updates

\begin{abstract}
This study investigates how the commitment of firms under competition influences environmental sustainability investment, pricing decisions, and profits of firms. We consider a stylized model where two firms compete in the market and examine three scenarios: (1) both firms commit, (2) only a single firm commits, and (3) neither firm commits. Interestingly, we find that commitment to sustainability investment by all firms results in the lowest sustainability investment in the industry. However, when a commitment is only made by one firm, sustainability investment in the industry can be the highest. Compared with under the no commitment scenario, a committed firm obtains a higher profit regardless of whether the commitment is also made by the competitor, but the competitor may become more profitable than the committed firm when it does not make a commitment. Although commitment by all firms yields the largest profits, it is the least effective from the entire societal perspective, resulting in both the lowest social welfare and the lowest sustainability investment. Instead, commitment by a single firm or no commitment can be the most effective for the entire society. We also discuss the implications of the investment efficiency of sustainability and consumer taste preference.
\end{abstract}

Keywords: environmental sustainability; commitment; competition; sustainability investment; climate change

\section{Introduction}

Climate change has emerged as an important issue in recent years and firms increasingly consider climate change as a strategic matter that they have to address [1,2]. Climate change issue influences consumers' purchasing decisions and thereby changes the competitive business environment. According to Nielsen's survey, $45 \%$ of consumers state that their purchasing decisions are affected by whether a product is produced by environmentally friendly companies [3]. More than half of all Global 500 firms also responded that these changing consumer behaviors are important driving forces for climate change action [4]. As a result, firms are investing more aggressively in improving their environmental sustainability level.

One notable trend in industries with regard to the firm's sustainability investment is that more firms are committing to the degree to which it will invest in sustainability initiatives in advance. In 2015, Siemens committed to being carbon neutral by 2030 by investing $€ 100$ million [5]. The company also specified to which programs the budget will be invested to achieve the goal. Siemens' commitment to environmental initiatives received attention from the media, and the company also proactively utilized it as an opportunity to appeal to environmentally-conscious consumers. Many other companies across diverse industries also announced long-term strategies with details on how their strategies will be implemented. For instance, Walmart committed to reducing greenhouse gas emissions by 50 million 
metric tons in China by 2030 [6], and P\&G committed to a sustainability strategy toward 2030 including a plan to cut its emissions in half [7]. L'Oréal announced its sustainability commitment toward 2020, such as investing in a supplier sustainability program and reducing waste by $60 \%$ [8]. H\&M also committed to a long-term sustainability strategy, specifying future plans on the portion of recycled material, the tones of garments collected and the percent of facilities with water-efficient equipment [9].

The aforementioned examples suggest that firms increasingly decide the level of sustainability investment in advance, before they determine the complete courses of other actions, e.g., prices, on how to compete with rival firms afterwards. That is, more firms in competitive markets are adopting the commitment strategy to sustainability investment. In fact, commitment strategy has been recognized as one of the central factors playing a key role in competitive markets in economics and management literature [10-12]. However, despite this emerging practice and the importance of commitment strategy under competition, little is known on how the firm's commitment strategy would influence the sustainability investment of the committed firm itself as well as that of the competing firm and also influence prices and performance of firms under competition. Studies on the environmental sustainability in the competitive markets largely focus on consumer or regulatory characteristics [13-16] and studies on commitment mostly investigate commitment strategy with regard to decisions such as price or quantity [17-19], thus the impacts of the commitment in terms of sustainability dimension remain under-explored. We aim to fill this gap and provide insights on the firm's commitment to sustainability investment. Thus, we address the following research questions:

- How would the commitment to the sustainability investment of firms under competition influence firms' incentives to invest in environmental initiatives? Would it promote the sustainability investment of each firm under competition or lessen it? How would the sustainability investment at the industry level be affected?

- What are the impacts of the commitment on the equilibrium pricing decision and profits of each firm? From the societal perspective, would the commitment to the sustainability investment of competing firms be desirable or not?

- How would the efficiency of sustainability investment and consumer taste preferences influence the effects of commitment to sustainability investment under competition?

To answer these questions, we employ a stylized model, which consists of two firms that compete in the market and invest in initiatives to improve environmental sustainability. We consider three scenarios regarding the commitment of firms: i.e., both firms commit, only a single firm commits, and neither firm commits. Following the convention in the literature on commitment [12,19], commitment strategy is captured in our study by a two-stage noncooperative game: the committed firm sets the level of sustainability investment in the first stage which affects the price competition taking place in the second stage, whereas the non-committed firm decides the level of sustainability in the second stage.

We briefly summarize the key insights. First, the commitment of both firms results in the lowest sustainability investment of each firm and of the industry, compared to commitment by a single firm or no commitment. However, when commitment to sustainability investment is made only by a single firm, it may lead to the highest sustainability investment of the industry due to the committed firm's heavy investment, despite the competing firm's lowered investment. This provides an important insight that the current trend in industries toward committing their sustainability strategies has complicated effects: the commitment strategy can be desirable to the society in terms of the sustainability dimension only when it is used by a fraction of firms. However, if it is employed industry-wide (e.g., as an industry standard), it actually shrinks the sustainability investment in industries.

Second, the commitment of both firms leads to the highest profits for each firm under competition, hence the highest profits at the industry level. A firm that unilaterally commits to its sustainability investment can still obtain a larger profit than it does without commitment. Interestingly, however, such unilateral commitment may make its competitor more profitable than the committed firm itself. 
These results imply that commitment towards a sustainability strategy can generally correspond to firms' economic incentives, whereas it may have an unintended positive externality to the competing firm's profit.

Third, from the entire societal perspective, a commitment by all competing firms is the least effective scenario, as it results in the lowest social welfare and the lowest environmental sustainability. Instead, either a single firm's commitment or no commitment is the most effective scenario for the entire society.

Lastly, when sustainability investment becomes more costly, or when consumer taste preference becomes stronger, although the sustainability efforts of each firm may either increase or decrease depending on the commitment scenario, the profits of firms always increase because the heightened burden of inducing customers via sustainability investment mitigates competition in sustainability dimension.

Our study contributes to the literature is as follows. First, we enrich the literature on environmental sustainability by investigating the impacts of firm's commitment strategy, which is widely recognized as a critical factor influencing the competitive landscape in the economics and management literature. To the best of our knowledge, this study provides one of the first analytical models to investigate the impacts of the firm's commitment to sustainability investment, which is increasingly observed in industries.

Second, we identify two contrasting roles of commitment strategy in terms of sustainability investment in the competitive market. If the commitment strategy is adopted by a portion of firms, the commitment strategy can be utilized to encourage the sustainability investment; that is, the firm can use commitment strategy to preoccupy the high sustainability position, thus obtaining more pricing power. However, if the commitment strategy is adopted by all competing firms, then the commitment strategy discourages the sustainability investment; that is, firms under competition may jointly use commitment strategy as a means to cut costly sustainability investment, thus softening the competition between them.

Third, we show that a commitment strategy may not always bring societal benefit, although our result confirms the well-known notion of the economic virtue of commitment strategy [11]. We also show that the unilateral commitment may make the rival firm more profitable and may induce firms to differentiate from each other further, which implies that the commitment strategy can significantly influence how firms compete in the market.

Our study also provides practical implications for managers and regulators. For managers, our study suggests that the commitment to sustainability investment can be a rational choice for firms because it enlarges profits. However, there is a potential pitfall: the unilateral commitment can also make the rival firm to be more profitable than the committed firm under particular circumstances. Furthermore, to which level of sustainability investment the firm needs to set under commitment strategy varies depending on the context. Thus, managers need to decide whether and how to adopt the commitment strategy in careful consideration of the conditions under it is employed.

For regulators, our study suggests that it is important to understand correctly how commitment strategy may alter a firm's incentives to sustainability investment. In particular, our result suggests that if the commitment strategy is adopted by a portion of firms in the competitive market, the regulator may not need to intervene in the competitive market because the commitment strategy acts as a device to promote sustainability investment. However, when the commitment strategy becomes prevalent in the competitive market, the regulator should consider more active intervention because the commitment strategy can be used as a means to mitigate competition in sustainability dimension. In such circumstances, the regulator may consider more stringent penalties on sustainability violation or devise proper incentives such as subsidies to facilitate sustainability investment of firms.

The remainder of this paper is organized as follows. Section 2 reviews the related literature. Section 3 presents the model, and Section 4 analyzes the equilibrium under each scenario. Section 5 
compares the three commitment scenarios and discusses the effects of commitment. Section 6 concludes the paper.

\section{Literature Review}

This article mainly relates to two research streams: environmental sustainability under competition and the commitment of firms' decisions.

The first stream relates to the issues of environmental sustainability under firms' competition. Galbreth and Ghosh [15] consider the sustainability concern and awareness of consumers under horizontal competition in a duopoly. They find that, when awareness is sufficiently high, an increase in awareness can benefit all firms under competition even though the two firms differ in terms of their sustainability level. Chen et al. [13] examine optimal pricing and emissions reduction decisions of two manufacturers under competition when consumers are sensitive to price and carbon emission, and investigate the effects of production and emissions reduction efficiency and the power structure (i.e., balanced and imbalanced). They show that the strong market power of a firm does not always ensure more profits than the competitor with less power, and show that when a firm gains more market power, it tends to set a higher sales price and obtain greater profits but it may become less green. Clemenz [16] analyzes the impact of an eco-label on firms' investment on abatement in a duopoly market. They show that, while underinvestment in abatement is likely to occur in the case of end-of-pipe abatement, a clean technology approach for abatement may achieve a first best level depending on the consumer's willingness to pay for abatement. Yalabik and Fairchild [14] show that environmental competition can facilitate firms to invest more in the environment, and it may also improve the effectiveness of consumer or regulatory pressure on firms to improve the environmental performance. Dong and Zhong [20] consider a price competition between regional ports. They document the possibility of tacit collusion between the ports under certain conditions. In the context of a vertically competitive chain that consists of a manufacturer and a retailer, Ghosh and Shah [21] investigate the green innovation and pricing decisions under the decentralized and cooperative channel policy with diverse market power structures and propose the two-part tariff contract to coordinate the channel. Ma et al. [22] consider a manufacturer whose products are sold to consumers through a retailer or its direct online channel and show that carefully designed revenue sharing contract can improve both players' profits.

Our study contributes to this literature on the environmental sustainability under firms' competition by showing that commitment to sustainability investment may either facilitate or deter firms' sustainability investment depending on whether commitment is made by all or a portion of competing firms and on the level of sustainability investment efficiency and the strength of consumer's taste preference.

The second related stream is the commitment of the decisions of firms. In the literature, commitment refers to a firm's strategic behavior to set a course of action in advance, which is typically captured by a two-stage noncooperative game $[10,12,19]$. The literature has explored the effects of firms' commitment to diverse strategies. Gilbert and Cvsa [17] examine price commitment in a supply chain. They investigate whether a supplier should commit to its price as a means to facilitate downstream innovation or it should maintain a flexible pricing policy to respond to demand uncertainty. They show that, although commitment is preferred from the perspective of a downstream firm or a supply chain, it does not necessarily increase the profit of the supplier. Nasser and Turcic [18] analyze the quantity commitment decision under duopoly differentiated on a Hotelling line. They show that both firms choose to commit to a quantity under low product differentiation to mitigate the intense price competition. However, when product differentiation is high, asymmetric equilibrium may arise where one firm chooses to commit and the other firm chooses not to commit. Li [23] studies the supply base design and the pricing mechanism where a buyer can make a price commitment that can be renegotiated afterward. The study shows that a buyer can design the supply base and the pricing mechanism to facilitate supplier competition or to motivate cost-reduction effort, and the two dimensions are strategic complements. 
Different from prior studies that mostly focus on the price or quantity commitment, our study adds to the literature on firms' strategic commitment by considering the commitment sustainability investment, which is increasingly found in practice, for firms under competition.

\section{Model}

We consider a duopoly model where two firms compete in the market, selling one product respectively. Two competing firms invest in environmental initiatives (e.g., investing in wastewater treatment, developing greener technology, conducting research and development projects for increased energy efficiency, or implementing recycling programs). We denote $s_{i}$ as the overall degree of sustainability investment. A higher $s_{i}$ indicates the decision of the higher greenness level of a firm, which implies the larger investment for environmental initiatives. Following Hong and Guo [24] and Ghosh and Shah [21,25], we assume that the sustainability investment $s_{i}$ incurs the investment cost of $k_{i} s_{i}^{2}$. A quadratic investment cost of sustainability efforts indicates a decreasing marginal return of investment activities. For instance, rational managers will target "low-hanging fruit" first, so that further improvements in environmental sustainability becomes increasingly difficult.

Consumers have different taste preferences, e.g., heterogeneous brand preference [26,27], which are distributed uniformly on a Hotelling line of unit length. Dating back to the seminal work by Hotelling [28], the Hotelling model has been widely utilized in industrial economics to model a duopoly industry of two competing firms that sell to heterogeneous consumers (See Martin [29] and Tirole [30] for a thorough review of the Hotelling models and extensions). For analytical simplicity, we normalize the length of the Hotelling line to one, following Desai [31], Caldieraro [26] and Liu and Tyagi [32]. We assume that firms are located at the extreme points of the line; firm 1 is located at $x=0$ and firm 2 is located at $x=1$. Each consumer incurs a cost $d \hat{x}$, where $d$ denotes a transportation cost parameter, representing the strength of consumers' taste preferences on its utility [31]. Consumer taste preference has been considered important in the studies on competition [26,31] because it indicates the extent to which consumer may choose the product that fits less to the ideal preference. More specifically, stronger consumer taste preference implies that the decisions of competing firms, i.e., price and sustainability investment in our study, have relatively fewer impacts on consumers' buying decision, thus it is difficult to induce customers that are close to the competitor. The Hotelling distance is denoted as $\hat{x}: \hat{x}=x$ if the consumer with the preference being located at $x$ buys a product from firm 1 , and $\hat{x}=1-x$ if the consumer buys a product from firm 2 . Consumers also have a different marginal utility of sustainability improvement, $\theta$, which is uniformly distributed over $[0,1]$.

Similar to Tyagi [33] and Clemenz [16], a consumer located at $(x, \theta)$ and buys from firm $i$ thus derives the following utility

$$
V+\theta s_{i}-p_{i}-d \hat{x}
$$

where $p_{i}$ is the price of a product from firm $i$. That is consumer utility from buying the product of firm $i$ decreases with the sales price $p_{i}$ and increases with the sustainability investment $s_{i}$. Here, $V$ denotes consumers' reservation value from the consumption of the product, and we assume that $V$ is assumed to be sufficiently large to ensure complete market coverage. This assumption is frequently adopted in the literature [32] and enables us to focus on the competition dynamics.

Using consumer utility defined above, we now derive the consumer demand for firm 1 and 2. To do so, we calculate the location of consumer $(\bar{x}, \bar{\theta})$ where the consumer is indifferent between buying the product of firm 1 and buying the product of firm 2. By solving $V+\bar{\theta} s_{1}-p_{1}-d \bar{x}=$ $V+\bar{\theta} s_{2}-p_{2}-d(1-\bar{x})$, we obtain the function of $\bar{\theta}(\bar{x})$ for a given $\bar{x}$ as follows:

$$
\bar{\theta}(\bar{x})=\left(p_{1}-p_{2}-d+2 d \bar{x}\right) /\left(s_{1}-s_{2}\right) .
$$

Then, let $x_{0}$ denote the $\bar{x}$ that satisfies $\bar{\theta}(\bar{x})=0$, and $x_{1}$ denote the $\bar{x}$ that satisfies $\bar{\theta}(\bar{x})=1$. It is easily derived that $x_{0}=\left(p_{2}-p_{1}+d\right) /(2 d)$ and $x_{1}=\left(s_{1}-s_{2}+p_{2}-p_{1}+d\right) /(2 d)$. Figure 1 illustrates the demand structure based on Equation (1). The line represents the indifference condition between 
two firms. The square in Figure 1 is divided into two regions. The area to the left of the diagonal line indicates the consumers who obtain higher utility from buying from firm 1 while the area to the right of the diagonal line indicates the consumers who obtain higher utility from buying from firm 2 . Since the market size is normalized to one and the area to the left (right) of the diagonal line in Figure 1 indicates consumers buying from firm 1 (firm 2), the market demand $q_{1}$ for firm 1 and the market demand $q_{2}$ for firm 2 are then obtained as follows:

$$
\begin{aligned}
& q_{1}=\left[2\left(p_{2}-p_{1}\right)+2 d+\left(s_{1}-s_{2}\right)\right] /(4 d) \\
& q_{2}=\left[2\left(p_{1}-p_{2}\right)+2 d-\left(s_{1}-s_{2}\right)\right] /(4 d) .
\end{aligned}
$$

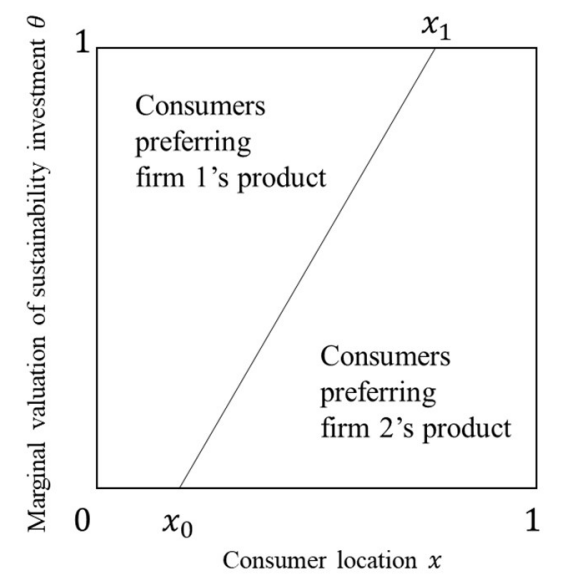

Figure 1. Illustration of the distribution of consumers. Note: This figure is revised and adapted from Clemenz [16].

Before firms decide the sales price and sell their products to consumers, each firm may commit to their sustainability investment in advance. Thus, the competition between two firms is modeled as a two-stage game, where each firm may commit to the respective sustainability investment $s_{i}$ in stage 1 , and chooses sales price $p_{i}$ in stage 2 . If a firm does not commit to sustainability investment in stage 1 , the firm decides its sustainability investment in stage 2 . This follows the commonly utilized method of operationalizing commitment strategy using the decision sequence: the committed firm chooses the decision variable in the first stage, taking the Stackelberg leadership, whereas the non-committed firm sets the decision variable in the second stage, reacting to the committed firm's decision $[11,12,19]$. Consumers purchase the product that provides the higher utility.

To elaborate on the effects of commitment for competing firms, we analyze three scenarios:

1. Both firms commit to sustainability investment.

2. Only a single firm commits to sustainability investment.

3. Neither firm commits to sustainability investment.

For notational convenience, the superscript " $\mathrm{BC}$ " refers to the scenario where both firms commit, the superscript "SC" refers to the scenario where only a single firm (i.e., firm 1) commits and the superscript " $\mathrm{N}$ " refers to the scenario where neither firm commits sustainability investment.

In each commitment scenario, firm $i^{\prime}$ s profit $\pi_{i}$ is given as $(i=1,2)$ :

$$
\pi_{i}=p_{i} q_{i}-k_{i} s_{i}^{2}=p_{i}\left[2\left(p_{3-i}-p_{i}\right)+2 d+\left(s_{i}-s_{3-i}\right)\right] /(4 d)-k_{i} s_{i}^{2} .
$$

In the ensuing analysis, we assume equivalent parameter values for both firms, that is, $k_{i} \equiv k, i=1,2$, so that any difference between sustainability investment and pricing decisions directly stem from different commitment scenarios, not from arbitrary choices in parameter values. 
Without a loss of generality, a marginal production cost is normalized to zero for each firm. This assumption does not affect the key insights of the study. To make our analysis tractable, we impose the following technical assumption:

Assumption 1. $d k \geq(2+\sqrt{31}) / 144$.

Assumption 1 ensures that $0 \leq x_{0}, x_{1} \leq 1$ holds. That is, among consumers located on the Hotelling line at any given $\theta$, a portion of them buys from firm 1 while the others buy from firm 2 . In other words, consumers located at the extreme points of the Hotelling line $(x=0,1)$ have a strong brand preference so that they always behave in line with their own tastes. There are many examples in practice. For instance, some Apple customers have a strong brand preference for Apple products and do not switch to products of other firms [34]. Assumption 1 also ensures that sales prices, sustainability investment, and the profits of firms remain nonnegative regardless of the commitment scenario.

\section{Analysis of Equilibrium}

In this section, we analyze the three commitment scenarios by backward induction. Unless stated otherwise, proofs of theorems and propositions are provided in Appendix A.

\subsection{Both Firms Commit (Scenario BC)}

We begin by analyzing the scenario where both firms commit to their sustainability investment. In the second stage, each firm decides its sales price to maximize individual profit described in (4) in consideration of the committed sustainability strategy of the competing firm. Since $\partial^{2} \pi_{i} / \partial p_{i}^{2}=$ $-1 / d<0$, solving $\partial \pi_{i} / \partial p_{i}=0$ yields the best response sales price:

$$
p_{i}\left(s_{i}, s_{3-i}\right)=\left(6 d+s_{i}-s_{3-i}\right) / 6 .
$$

From Equation (5), a sales price of firm $i$ increases in the relative sustainability investment, i.e., $s_{i}-s_{3-i}$, which incentivizes firms to commit to sustainability efforts. In the first stage, both firms commit to their sustainability investment anticipating the best response sales prices of each other. Substituting Equation (5) into Equation (4) and solving $\partial \pi_{i} / \partial s_{i}=0$ yields equilibrium sustainability investment. Sufficient conditions for optimality are satisfied, i.e., $\partial^{2} \pi_{i} / \partial s_{i}^{2}=-(72 d k-1) / 36 d<0$. Proposition 1 summarizes the equilibrium outcomes under the commitment of both firms.

Proposition 1. When both firms commit to sustainability investment, firm i's equilibrium sustainability investment is $s_{i}^{B C *}(d, k)=1 / 12 k$, equilibrium sales price is $p_{i}^{B C *}(d, k)=d$, and profit is $\pi_{i}^{B C *}(d, k)=$ $(72 d k-1) / 144 k$

When both firms commit to their sustainability investment, the equilibrium $s_{i}^{B C *}$ decreases in the cost parameter of sustainability investment $k$, which is intuitive in that sustainability investment becomes more costly. The equilibrium $p_{i}^{B C *}$ is proportional to $d$. We will discuss the underlying reason in Theorem 1.

For this scenario of bilateral commitment, we further investigate the effects of key parameter values, i.e., $k, d$, on the equilibrium outcomes. Differentiating the equilibrium outcomes in Proposition 1 with respect to $k$ and $d$ leads to the results in Theorem 1. The derivation of the results is straightforward and is hence omitted.

Theorem 1. When both firms commit to sustainability investment:

(i) $\partial s_{i}^{B C *} / \partial k<0 ; \partial p_{i}^{B C *} / \partial k=0 ; \partial \pi_{i}^{B C *} / \partial k>0$

(ii) $\partial s_{i}^{B C *} / \partial d=0 ; \partial p_{i}^{B C *} / \partial d>0 ; \partial \pi_{i}^{B C *} / \partial d>0$ 
It may seem counter-intuitive that higher $k$ leads to higher $\pi_{i}^{B C *}$. The underlying reason is that the lower efficiency of sustainability investment serves as an instrument that mitigates firms' competition on the sustainability domain, inducing both firms to commit lower $s_{i}^{B C *}$. This effect of mitigated competition outweighs the effect of the higher investment cost parameter, thus profits of both firms increase in $k$.

At the same time, the sales prices of both firms increase in $d$. This is because higher $d$ implies that each consumer has a relatively strong taste preference, thus consumers are less likely to switch to a product of the firm that matches their preferences less. This makes consumers less sensitive to price differences between firms, and each firm has greater pricing power over consumers. This leads to higher $p_{i}^{B C *}$ and $\pi_{i}^{B C *}$.

\subsection{Only a Single Firm Commits (Scenario SC)}

Suppose that without a loss of generality, firm 1 commits to its sustainability investment but firm 2 does not. Then, in the second stage, firm 1 decides its sales price whereas firm 2 decides its sales price and sustainability investment for a given $s_{1}$. The best response functions are obtained as follows:

$$
\begin{gathered}
p_{1}\left(s_{1}\right)=2 d\left(24 d k+4 k s_{1}-1\right) /(48 d k-1), \\
p_{2}\left(s_{1}\right)=8 d k\left(6 d-s_{1}\right) /(48 d k-1), \\
s_{2}\left(s_{1}\right)=\left(6 d-s_{1}\right) /(48 d k-1) .
\end{gathered}
$$

It is easily derived that $\partial^{2} \pi_{1} / \partial p_{1}^{2}=-1 / d<0$. Since the Hessian matrix of the objective function of firm 2 is addressed as $\left|H_{1}\right|=-1 / d<0$ and $\left|H_{2}\right|=(32 d k-1) / 16 d^{2}<0$, the Hessian matrix is negative-definite. In the first stage, firm 1 commits its sustainability investment in anticipation of the best response functions in Equations (6)-(8). Proposition 2 summarizes the equilibrium outcomes under unilateral commitment by firm 1 .

Proposition 2. When only firm 1 commits to sustainability investment, firm 1's equilibrium sustainability investment is $s_{1}^{S C *}(d, k)=8 d(24 d k-1) /\left(1-128 d k+2304 d^{2} k^{2}\right)$, equilibrium sales price is $p_{1}^{S C *}(d, k)=2 d(24 d k-1)(48 d k-1) /\left(1-128 d k+2304 d^{2} k^{2}\right)$, and profit is $\pi_{1}^{S C *}(d, k)=2 d(24 d k-1)^{2} /\left(1-128 d k+2304 d^{2} k^{2}\right)$. Firm 2's equilibrium sustainability investment is $s_{2}^{S C *}(d, k)=2 d(144 d k-7) /\left(1-128 d k+2304 d^{2} k^{2}\right)$, equilibrium sales price is $p_{2}^{S C *}(d, k)=16 d^{2} k(144 d k-7) /\left(1-128 d k+2304 d^{2} k^{2}\right)$, and profit is $\pi_{2}^{S C *}(d, k)=$ $4 d^{2} k(144 d k-7)^{2}(32 d k-1) /\left(1-128 d k+2304 d^{2} k^{2}\right)^{2}$.

From Equation (6), commitment to higher sustainability investment increases consumers' utility from buying a product of firm 1, thus facilitates a higher sales price of firm 1, other things being equal. We also note that firm 2's sustainability strategy may be the opposite of firm 1. In Equations (7) and (8), other things being equal, commitment to a higher sustainability investment by firm 1 has a negative effect on firm 2's sustainability investment and also on firm 2's sales price. This implies that firm 1's unilateral commitment to sustainability investment may induce the competing firm to differentiate further.

We now investigate the equilibrium outcomes with regard to the key parameters $k$ and $d$ in the following theorem.

Theorem 2. When only firm 1 commits to sustainability investment:

(i) $\partial s_{1}^{S C *} / \partial k<0 ; \partial p_{1}^{S C *} / \partial k<0$ if $d k<(3+\sqrt{2}) / 48$, and $\partial p_{1}^{S C *} / \partial k>0$ otherwise; $\partial \pi_{1}^{S C *} / \partial k>0$;

(ii) $\partial s_{2}^{S C *} / \partial k>0$ if $d k<(7+\sqrt{2}) / 144$, and $\partial s_{2}^{S C *} / \partial k<0$ otherwise; $\partial p_{2}^{S C *} / \partial k>0$ if $d k<$ $(3+\sqrt{2}) / 48$, and $\partial p_{2}^{S C *} / \partial k<0$ otherwise $\partial \pi_{2}^{S C *} / \partial k>0$; 
(iii) $\partial s_{1}^{S C *} / \partial d<0 ; \partial p_{1}^{S C *} / \partial d<0$ if $d k<t_{1}^{S C}$, and $\partial p_{1}^{S C *} / \partial d>0$ otherwise; $\partial \pi_{1}^{S C *} / \partial d>0$;

(iv) $\partial s_{2}^{S C *} / \partial d>0$ if $d k<(3+\sqrt{2}) / 48$, and $\partial s_{2}^{S C *} / \partial d<0$ otherwise; $\partial p_{2}^{S C *} / \partial d>0 ; \partial \pi_{2}^{S C *} / \partial d>0$;

where $t_{1}^{S C}=\left(8+\sqrt{v^{S C}}+\sqrt{30-v^{S C}+52 / \sqrt{v^{S C}}}\right) / 288$, and $v^{S C}=10+3(39-6 \sqrt{22})^{1 / 3}+$ $3(39+6 \sqrt{22})^{1 / 3}$.

In this scenario of unilateral commitment, the negative effect of $k$ on sustainability investment continues to hold for firm 1, as discussed under the bilateral commitment scenario in Section 4.1. Interestingly, however, higher $k$ may lead to a greater sustainability investment of firm 2 because although higher $k$ increases firm 2's burden of sustainability investment, it also induces firm 1 to commit to lower sustainability investment. It thus becomes relatively easier for firm 2 to catch up to firm 1 in terms of sustainability dimension. The latter effect tends to dominate the former effect, which leads to higher $s_{2}^{S C *}$ under higher $k$ when $k$ and $d$ remain relatively low.

Higher $k$ has two effects on the pricing decision of firm 1: it raises the investment cost for a given sustainability investment level, but it decreases sustainability investment and hence lowers consumer utility. For firm 1, the latter effect outweighs the former effect when $k$ and $d$ are relatively low, leading to a lower sales price. However, the opposite holds under large $k$ and $d$. In contrast, firm 2 increases its sales price in $k$ when $k$ and $d$ are relatively low because $s_{2}^{S C *}$ increases as discussed above, and thus a firm compensates for higher sustainability investment costs via a higher price. In terms of profits, firm 1 's and firm 2's profits increase in $k$, which is similar to the bilateral commitment scenario.

An increase of $d$ generally reduces the sustainability investment of firms, which is also similar to bilateral commitment. When $k$ and $d$ are relatively low, firm 2 may increase $s_{2}^{S C *}$ in $d$ in response to a decrease of $s_{1}^{S C *}$. However, firm 2 also reduces its sustainability investment otherwise. Furthermore, higher $d$ generally facilitates a higher sales price because consumers become relatively less sensitive to price differences. Thus, the profits of both firms increase in $d$.

Figure 2 depicts the effects of $k$ and $d$ on the equilibrium behavior under unilateral commitment, which confirms the results in Theorem 2. Figure 2a also shows that when $k$ becomes substantially large, the two firms become similar in terms of their pricing and sustainability strategies. For instance, $\lim _{k \rightarrow \infty} s_{1}^{S C *}=\lim _{k \rightarrow \infty} s_{2}^{S C *}=0$ and $\lim _{k \rightarrow \infty} p_{1}^{S C *}=\lim _{k \rightarrow \infty} p_{2}^{S C *}=d$. This implies that the high burden of sustainability investment prevents firm 1 to make use of advantages from its unilateral commitment (e.g., preoccupying high sustainability position). As a result, the two firms become less differentiated despite the unilateral commitment by firm 1 . However, Figure $2 \mathrm{~b}$ shows that, although $d$ becomes very large, the two firms remain substantially differentiated in terms of sustainability strategies, e.g., $\lim _{d \rightarrow \infty} s_{1}^{S C *}=1 / 12 k$ and $\lim _{d \rightarrow \infty} s_{2}^{S C *}=1 / 8 k$.

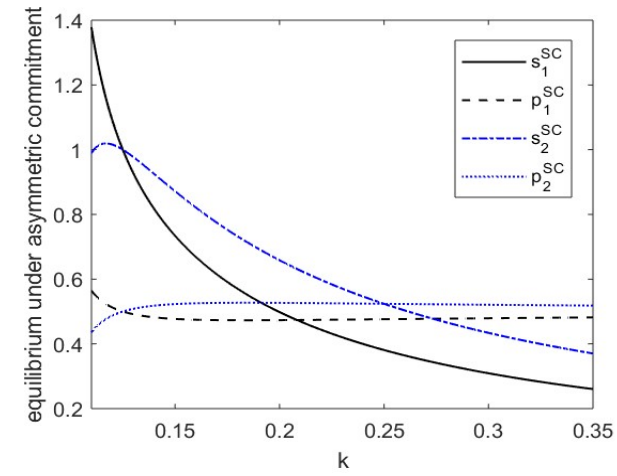

(a)

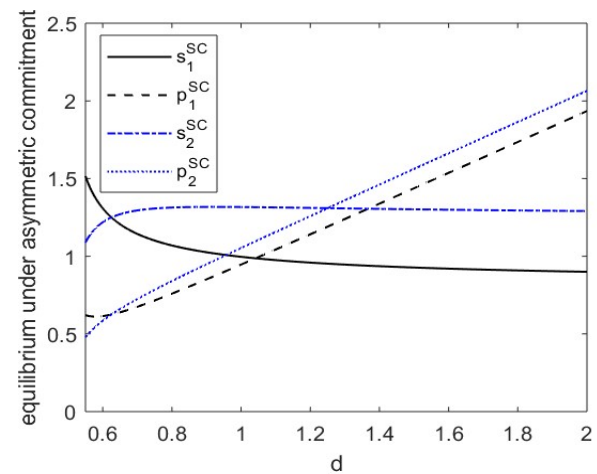

(b)

Figure 2. Effects of $k$ and $d$ on the equilibrium decisions under unilateral commitment by firm 1 : (a) Effects of $k$; (b) effects of $d$. Note: $d=0.5$ in (a) and $k=0.1$ in (b). 


\subsection{Neither Firm Commits (Scenario N)}

In this scenario, neither firm commits to its sustainability investment in advance. Thus, firm 1 and firm 2 determine sustainability investment and sales price simultaneously to maximize their individual profits in Equation (4). Proposition 3 summarizes the equilibrium outcomes under no commitment. The equilibrium strategies are derived by solving first-order conditions $\partial \pi_{i} / \partial s_{i}=0$ and $\partial \pi_{i} / \partial p_{i}=0$. These strategies are optimal because the objective function of firm $i$ is jointly concave in $\left(s_{i}, p_{i}\right)$.

Proposition 3. When neither firm commits to sustainability investment, firm i's equilibrium sustainability investment is $s_{i}^{N *}(d, k)=1 / 8 k$, equilibrium sales price is $p_{i}^{N *}(d, k)=d$, and profit is $\pi_{i}^{N *}(d, k)=$ $(32 d k-1) / 64 k$.

In this scenario, the equilibrium sustainability investment is inversely related to the cost parameter $k$, while the equilibrium sales price is influenced by consumers' taste preferences $d$, similar to the bilateral commitment.

Differentiating the equilibrium outcomes in Proposition 3 with respect to $k$ and $d$ leads to the following theorem. The derivation is straightforward and is hence omitted.

Theorem 3. When neither firm commits to sustainability investment:

(i) $\partial s_{i}^{N *} / \partial k<0 ; \partial p_{i}^{N *} / \partial k=0 ; \partial \pi_{i}^{N *} / \partial k>0$

(ii) $\partial s_{i}^{N *} / \partial d=0 ; \partial p_{i}^{N *} / \partial d>0 ; \partial \pi_{i}^{N *} / \partial d>0$

Theorem 3 confirms the observations under bilateral commitment and the part of them under unilateral commitment by firm 1 . While the sustainability investment of both firms decreases in $k$, the effect of the mitigated competition on the sustainability dimension outweighs the cost burden of higher $k$, thus both firms benefit from an increase in $k$. Furthermore, an increase in $d$ promotes firms to raise the sales price, which leads to larger profits for both firms.

\section{Comparisons between Commitment Scenarios}

We now analyze the effects of commitment on sustainability investment, sales price, and profits by comparing the three scenarios discussed above. Theorem 4 summarizes the comparison results in terms of sustainability investment. Recall that we use the notations ' $\mathrm{BC}^{\prime}$, ' $\mathrm{SC}$ ', and ' $\mathrm{N}$ ' to indicate the scenarios of (1) both firms commit, (2) only a single firm commits, and (3) neither firm commits, respectively.

In what follows, we let

$$
\mathcal{H} \equiv d k
$$

which summarizes the effects of the strength of consumer's taste preference and the investment cost coefficient. Then, a higher $\mathcal{H}$ corresponds to the context with stronger taste preference of consumers and/or costlier sustainability investment, which implies that it becomes more burdensome for firms to attract consumers that are closer to the competitor via sustainability investment. In contrast, a lower $\mathcal{H}$ implies that taste preferences of consumers are relatively weak and/or sustainability investment is affordable, thus, sustainability investment is more likely to be utilized as a measure to take consumers from the competitor.

Theorem 4. The competing firms' equilibrium sustainability investment under the three scenarios satisfy the following relationships:

(i) $s_{1}^{B C}<s_{1}^{N}<s_{1}^{S C}$ if $\mathcal{H}<1 / 16, s_{1}^{B C}<s_{1}^{S C}<s_{1}^{N}$ otherwise;

(ii) $s_{2}^{B C}<s_{2}^{S C}<s_{2}^{N}$ if $\mathcal{H}<1 / 16$, and $s_{2}^{B C}<s_{2}^{N}<s_{2}^{S C}$ otherwise;

(iii) $s_{2}^{S C}<s_{1}^{S C}$ if $\mathcal{H}<1 / 16$, and $s_{1}^{S C}<s_{2}^{S C}$ otherwise;

(iv) $\sum s_{i}^{B C}<\sum s_{i}^{N}<\sum s_{i}^{S C}$ if $\mathcal{H}<1 / 16$, and $\sum s_{i}^{B C}<\sum s_{i}^{S C}<\sum s_{i}^{N}$ otherwise $(i=1,2)$. 
From Theorem 4 (i) and (ii), we note that the scenario where both firms commit to sustainability investment results in the lowest sustainability investment of each firm. That is, under the context of horizontal competition, if the commitment is made by both firms, it serves as a device to mitigate competition in sustainability improvement. This result is different from Gilbert and Cvsa [17], where commitment is utilized by a firm to facilitate its partner's innovation under the context of vertical competition.

However, if the commitment is made by a single firm only (i.e., firm 1), such unilateral commitment may provide the committed firm with the strongest incentive to invest in sustainability (see Figure 3a). In this case, the committed firm preoccupies the position of high sustainability in advance, discouraging the competing firm from investing in environmental initiatives in the second stage. This result is observed under relatively low $\mathcal{H}$, where the committed firm can attract customers from the competitor more effectively via its position of high sustainability. In contrast, under relatively high $\mathcal{H}$, the unilateral commitment by firm 1 reduces firm 1's sustainability investment compared to under no commitment, while facilitating firm 2 to raise its sustainability investment to differentiate itself from firm 1 . Theorem 4 (ii) and (iii) also show that, as a result, the sustainability investment of firm 2 may even become greater than the sustainability investment of firm 1 and also greater than the sustainability investment of each firm under bilateral commitment and under no commitment.

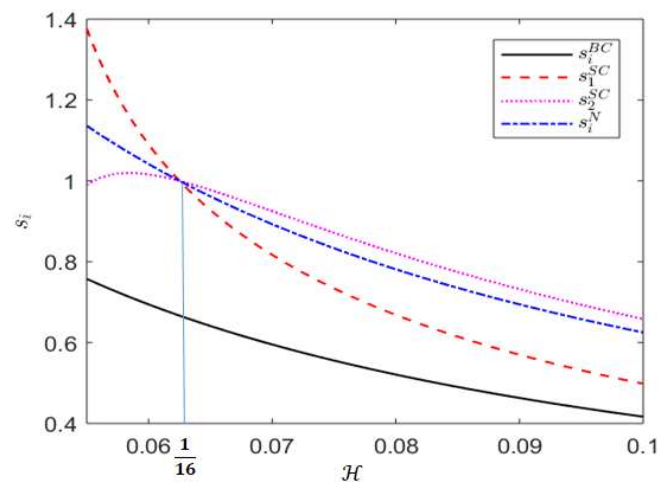

(a)

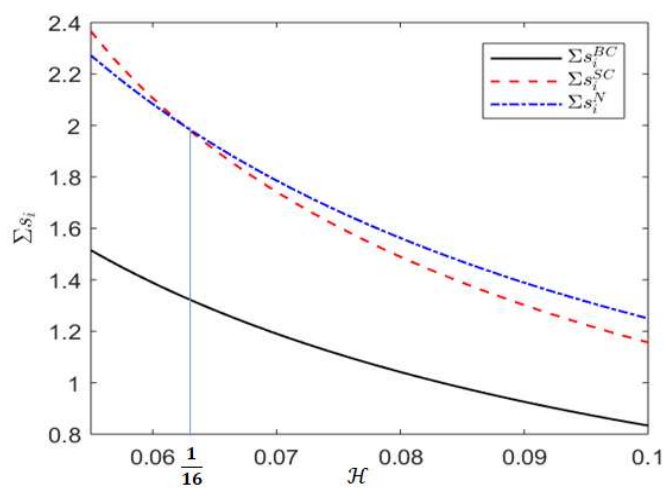

(b)

Figure 3. Comparisons of sustainability investment between different commitment scenarios: (a) Comparison of $s_{i} ;(\mathbf{b})$ comparison of $\sum s_{i}$. Note: $d=0.5$ and $k \in[0.11,0.2]$.

In the industry level, Theorem 4 (iv) shows that the total sustainability investment is the highest under unilateral commitment or no commitment, and it is the lowest under bilateral commitment. Thus, commitment may fail to promote firms to invest more in environmental initiatives, especially when it is made by all competing firms. However, when commitment is not made by the competitor, the committed firm may heavily invest in environmental initiatives to obtain a competitive advantage over the competitor. Thus, high sustainability investment under unilateral commitment may make the sustainability investment in the industry the highest among all the scenarios (Figure 3b).

We then compare the equilibrium sales prices under the three scenarios in the following theorem.

Theorem 5. The competing firms' equilibrium sales prices under the three scenarios satisfy the following relationship: $p_{2}^{S C}<p_{i}^{B C}=p_{i}^{N}<p_{1}^{S C}$ if $\mathcal{H}<1 / 16$, and $p_{1}^{S C}<p_{i}^{B}=p_{i}^{N}<p_{2}^{S C}$ otherwise.

Theorem 5 shows that the equilibrium sales price of each firm becomes either the highest or the lowest under the commitment by a single firm and the sales prices under bilateral commitment and no commitment are intermediate. Compared with Theorem 4, this result implies that unilateral commitment induces two competing firms sufficiently differentiated. That is, one firm occupies a high price and high sustainability position while the competing firm occupies a low price and low sustainability position. The position each firm takes depends on the level of $\mathcal{H}$. 
Theorem 6 summarizes the comparison results of equilibrium profits.

Theorem 6. The competing firms' equilibrium profits under the three scenarios satisfy the following relationships:

(i) $\pi_{1}^{N}<\pi_{1}^{S C}<\pi_{1}^{B C}$;

(ii) $\pi_{2}^{S C}<\pi_{2}^{N}<\pi_{2}^{B C}$ if $\mathcal{H}<1 / 16$, and $\pi_{2}^{N}<\pi_{2}^{S C}<\pi_{2}^{B C}$ otherwise;

(iii) $\pi_{1}^{S C}>\pi_{2}^{S C}$ if $\mathcal{H}<1 / 16$, and $\pi_{1}^{S C}<\pi_{2}^{S C}$ otherwise;

(iv) $\sum \pi_{i}^{S C}<\sum \pi_{i}^{N}<\sum \pi_{i}^{B C}$ if $\mathcal{H}<1 / 16$, and $\sum \pi_{i}^{N}<\sum \pi_{i}^{S C}<\sum \pi_{i}^{B C}$ otherwise $(i=1,2)$.

Theorem 6 shows that firms under competition have incentives to make a commitment to sustainability investment. In terms of firm 1, it obtains a larger profit from its unilateral commitment than it does without commitment, implying that unilateral commitment provides the first-mover advantage to the committed firm. When both firms commit to sustainability strategies, all firms obtain larger profits under bilateral commitment than under unilateral commitment. That is, the commitment by all firms yields the largest profit to each firm, and hence the largest industry profits (see Figure 4). Under bilateral commitment, although commitment no longer ensures the first-mover position to any firm, making a commitment is profitable because both firms can commit to relatively low sustainability efforts.

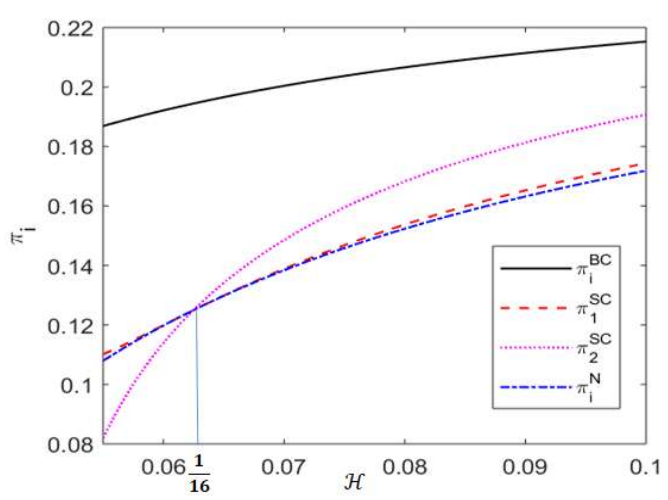

(a)

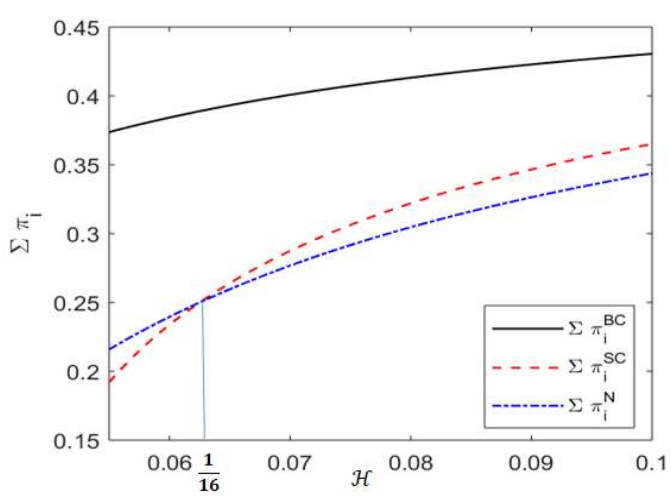

(b)

Figure 4. Comparisons of profits between different commitment scenarios: (a) Comparison of $\pi_{i}$; (b) comparison of $\sum \pi_{i}$. Note: $d=0.5$ and $k \in[0.11,0.2]$.

Interestingly, a unilateral commitment by firm 1 may also benefit firm 2. In fact, firm 1's unilateral commitment may make firm 2 more profitable than firm 1. Although firm 1 also benefits from commitment, it reduces its sustainability investment substantially under high $\mathcal{H}$ (refer to Theorem 4). Then, firm 2 can choose a relatively high sales price and high sustainability investment, while it differentiates itself sufficiently from firm 1 . As a result, firm 2 may obtain a larger profit than firm 1 . The industry profits may also become larger under unilateral commitment than under no commitment. However, under low $\mathcal{H}$, while firm 1's profit becomes larger, firm 2's profit becomes smaller. Thus, the industry profits may be the smallest under unilateral commitment compared to under bilateral commitment or no commitment.

The following theorem presents the relative effect of bilateral commitment to no commitment. It shows how commitment to sustainability investment by all firms can influence the total sustainability investment and total profits in the industry.

Theorem 7. Let $\Delta s=\sum s_{i}^{B C} / \sum s_{i}^{N}$ and $\Delta \pi=\sum \pi_{i}^{B C} / \sum \pi_{i}^{N}$. Then, $\Delta s=2 / 3$ and $\Delta \pi \epsilon$ $(1,2(62+5 \sqrt{31}) / 99]$. Furthermore, $\Delta \pi$ decreases in $k$ and $d$. 
Theorem 7 shows that when all competing firms commit to sustainability investment, the sustainability investment in the entire industry decreases by $1 / 3$, compared to when neither firm commits, which implies a significant degradation in the sustainability dimension due to the commitment. In contrast, the commitment by all firms improves the economic performance of the industry substantially, up to $200(62+5 \sqrt{31}) / 99 \%(\approx 181.49 \%)$. The economic virtue of bilateral commitment is lessened under high $k$ and $d$ because under such circumstances, competing firms have to bear relatively greater costs to induce consumers through pricing or sustainability decisions. Thus, this theorem confirms that commitment to sustainability investment may not contribute to sustainability improvement but instead may improve economic efficiency in the industry.

From Theorems 4 and 6, we have shown that improvement of total sustainability investment coincides with the loss of total profits in the industry level. It implies that there is a trade-off between sustainability and economic performance. However, from a societal perspective, there is another important stakeholder, i.e., consumers. Thus, we analyze consumer surplus and examine the effects of commitment on consumer surplus. For analytical tractability, we denote $\bar{x}(\theta)=$ $\left[\left(s_{1}-s_{2}\right) \theta+d-\left(p_{1}-p_{2}\right)\right] / 2 d$ from Equation (1), which indicates that the consumer at $x=\bar{x}(\theta)$ is indifferent between buying the product of firm 1 and buying the product of firm 2 , for a given $\theta$.

Under the bilateral commitment scenario, from the equilibrium outcomes in Proposition $1, \bar{x}(\theta)=$ $1 / 2$ and the surplus of individual consumer located at $x$ for a given $\theta$ is as follows:

$$
S_{1}^{B C}(x ; \theta)=\left\{\begin{array}{c}
V+\theta / 12 k-d-d x, \quad \text { if } x \in[0,1 / 2], \\
V+\theta / 12 k-d-d(1-x), \quad \text { if } x \in(1 / 2,1] .
\end{array}\right.
$$

For a given $\theta$, we calculate $S_{2}^{B C}(\theta)$, which is obtained by integrating $S_{1}^{B C}(x ; \theta)$ over $x \in[0,1]$. Then, $S_{2}^{B C}(\theta)=V+\theta / 12 k-5 d / 4$. Next, we calculate consumer surplus under bilateral commitment by integrating $S_{2}^{B C}(\theta)$ over $\theta \in[0,1]$, which is given by:

$$
C S^{B C}=V-5 d / 4+1 / 24 k .
$$

Under unilateral commitment by a single firm, from the equilibrium outcomes in Proposition 2, the surplus of individual consumers located at $x$ for a given $\theta$ is as follows:

$$
S_{1}^{S C}(x ; \theta)=\left\{\begin{array}{cl}
V-\frac{d\left(2+x+2304 d^{2} k^{2}(1+x)+8 \theta-16 d k(9+8 x+12 \theta)\right)}{1-128 d k+2304 d^{2} k^{2}}, & \text { if } x \in[0, \bar{x}(\theta)], \\
V-\frac{d\left(1-2304 d^{2} k^{2}(x-2)-x+14 \theta+16 d k(8 x-3(5+6 \theta))\right)}{1-128 d k+2304 d^{2} k^{2}}, & \text { if } x \in(\bar{x}(\theta), 1] .
\end{array}\right.
$$

For a given $\theta$, we calculate $S_{2}^{S C}(\theta)$, which is obtained by integrating $S_{1}^{S C}(x ; \theta)$ over $x \in[0,1]$ :

$$
S_{2}^{S C}(\theta)=\frac{\left[\begin{array}{c}
-26,542,080 d^{5} k^{4}+4 V+147,456 d^{4} k^{3}(20+144 k V+15 \theta) \\
-d\left(1+1024 k V+68 \theta-36 \theta^{2}\right) \\
+64 d^{2} k\left(18+1312 k V+115 \theta-18 \theta^{2}\right)-512 d^{3} k^{2}\left(203+4608 k V+450 \theta-18 \theta^{2}\right)
\end{array}\right]}{4\left(1-128 d k+2304 d^{2} k^{2}\right)^{2}} .
$$

Then, consumer surplus under unilateral commitment is obtained by integrating $S_{2}^{S C}(\theta)$ over $\theta \in[0,1]:$

$$
C S^{S C}=V-\frac{d\left(23-4448 d k+216,064 d^{2} k^{2}-4,055,040 d^{3} k^{3}+26,542,080 d^{4} k^{4}\right)}{4\left(1-128 d k+2304 d^{2} k^{2}\right)^{2}} .
$$


Under the no commitment scenario, from the equilibrium outcomes in Proposition $3, \bar{x}(\theta)=1 / 2$ and the surplus of individual consumers located $x$ for a given $\theta$ is given by:

$$
S_{1}^{N}(x ; \theta)=\left\{\begin{array}{c}
V+\theta / 8 k-d-d x, \quad \text { if } x \in[0,1 / 2] . \\
V+\theta / 8 k-d-d(1-x), \quad \text { if } x \in(1 / 2,1] .
\end{array}\right.
$$

Then, for a given $\theta, S_{2}^{N}(\theta)=V+\theta / 8 k-5 d / 4$ is obtained by integrating $S_{1}^{N}(x ; \theta)$ over $x \in[0,1]$. Consumer surplus under no commitment is obtained by integrating $S_{2}^{N}(\theta)$ over $\theta \in[0,1]$ as follows:

$$
C S^{N}=V-5 d / 4+1 / 16 k \text {. }
$$

Then, we examine the effects of commitment from the holistic perspective in the following theorem. To facilitate interpretation, let $S W^{X}=\sum \pi_{i}^{X}+C S^{X}(X=B C, S C, N)$ denote the social welfare, which consists of the sum of firms' total profits and total consumer surplus in the industry.

Theorem 8. The competing firms' equilibrium outcomes under the three scenarios satisfy the following relationships:

(i) $C S^{B C}<C S^{N}<C S^{S C}$ if $\mathcal{H}<1 / 16$, and $C S^{B C}<C S^{S C}<C S^{N}$ otherwise;

(ii) $S W^{B C}<S W^{N}<S W^{S C}$ if $\mathcal{H}<(7+\sqrt{31}) / 144$, and $S W^{B C}<S W^{S C}<S W^{N}$ otherwise.

Theorem 8(i) shows that consumer surplus becomes the smallest under bilateral commitment and the largest under either unilateral commitment or no commitment. Compared with Theorem 4, we observe that the effects of commitment on consumer surplus qualitatively coincide with those on sustainability efforts at the industry level. Since consumer surplus is determined by both equilibrium sustainability efforts and sales price, this result also implies that commitment strategy has relatively more influence on the sustainability efforts than it does on the sales prices of firms.

Theorem 8(ii) further shows that the social welfare that consists of firms' profits and consumer surplus also becomes the smallest under the bilateral commitment, while it becomes the largest under either unilateral commitment or no commitment. When both firms commit, their total profits increase substantially as discussed in Theorem 6. However, a decrease in consumer surplus due to mitigated competition far outweighs an increase in profits, leading to lower social welfare. Thus, if we consider the social welfare for firms and consumers, it is more effective that firms do not commit to sustainability investment at all, or that only a single firm commits.

Then, what if we consider social welfare as well as the sustainability dimension? Table 1 summarizes the analytical results obtained so far, which provides a comprehensive picture of the effects of commitment on the entire society. The table shows that the effects of commitment can be categorized into three regions: Regions I, II, and III.

Table 1. Summary of the comparisons between the commitment scenarios.

\begin{tabular}{cccc}
\hline Comparisons & Region I & Region II & Region III \\
\cline { 2 - 4 } & $\mathcal{H}<1 / 16$ & $\boldsymbol{H} \in(1 / 16,(7+\sqrt{31}) / 144)$ & $\mathcal{H}>(7+\sqrt{31}) / 144)$ \\
\hline Total profits $\left(\sum \pi_{i}\right)$ & $S C<N<B C$ & $N<S C<B C$ & $N<S C<B C$ \\
Consumer surplus $(C S)$ & $B C<N<S C$ & $B C<S C<N$ & $B C<S C<N$ \\
Social welfare $(S W)$ & $B C<N<S C$ & $B C<N<S C$ & $B C<S C<N$ \\
Total sustainability investment $\left(\sum s_{i}\right)$ & $B C<N<S C$ & $B C<S C<N$ & $B C<S C<N$ \\
\hline
\end{tabular}

The most prominent observation from Table 1 is that commitment by all firms is the least effective scenario in terms of both economic and sustainability dimensions. In all regions, the bilateral commitment provides the lowest social welfare $\left(S W^{B C}\right)$ and the lowest sustainability efforts $\left(\sum s_{i}^{B C}\right)$. Thus, from the entire societal perspective, a commitment by all competing firms should be avoided. 
To enhance the effectiveness of the industry from the entire societal perspective, regulators or NGOs should encourage firms not to commit at all when firms experience difficulties in utilizing sustainability investment to attract customers, that is, sustainability investment is relatively costly and/or customers in the market have relatively strong taste preferences (Region III). When sustainability investment can be effectively utilized as a means to secure more customers, that is, sustainability investment is relatively affordable and/or customers have weak taste preferences (Region I), commitment by a single firm is the most effective scenario for the entire society, as it leads to the highest social welfare and the highest sustainability investment. In the intermediate region (Region II), either unilateral commitment or no commitment can be optimal for the entire society.

In Region II, whether unilateral commitment or no commitment is the optimal strategy from the holistic perspective depends on the value of the environmental impact. For instance, let $E S^{X}=S W^{X}+\varepsilon \sum s_{i}^{X}=\sum \pi_{i}^{X}+C S^{X}+\varepsilon \sum s_{i}^{X}(X=B C, S C, N)$, where ES denotes environmental social welfare, and $\varepsilon$ translates the value of firms' environmental investment into monetary terms, following Hong and Guo [24] and Krass et al. [35]. Then, it is clear that in Region II, no commitment leads to the highest $E S$ if $\varepsilon$ is sufficiently high, while unilateral commitment by a single firm leads to the highest $E S$ otherwise. It is also straightforward that unilateral commitment leads to the highest $E S$ in Region I, while no commitment leads to the highest ES in Region III, as discussed above.

\section{Discussion and Conclusions}

In this study, we have investigated how the commitment to sustainability investment influences sustainability and pricing strategy and the consequent profits of firms under competition. Two competing firms decide their own sustainability investment and sales price. We consider three scenarios where (1) both firms commit, (2) one firm commits while the other firm does not, and (3) neither firm commits to sustainability investment. We derive the equilibrium sustainability investment, sales prices, and firms' profits under each scenario and examine the characteristics of the equilibrium with respect to investment efficiency and consumer's taste preference. Then, we compare and discuss the equilibrium outcomes under the three scenarios in terms of sustainability investment, sales price, profits, consumer surplus, social welfare and environmental social welfare.

The major findings are summarized as follows:

- A firm's commitment to sustainability investment can have adverse effects on the sustainability investment in the industry, especially when such commitment is made by all competing firms. When both firms commit to sustainability investment, total sustainability investment in the industry decreases to $67 \%$ compared to that under no commitment. In this scenario of bilateral commitment, commitment is used as a device to soften competition in the sustainability dimension, and the sustainability investment of each firm usually becomes the lowest.

- When firm 1 unilaterally commits to sustainability investment, the total sustainability investment may remain lower than that under no commitment. However, unilateral commitment may sometimes increase total sustainability investment in the industry if the sustainability investment is relatively affordable and/or if consumers have relatively weak taste preferences. In this case, the committed firm utilizes its commitment strategy to attract more customers from the competitor via its high sustainability position; thus, it invests heavily in environmental initiatives. Consequently, the total sustainability investment in the industry may become the highest under unilateral commitment despite the relatively low sustainability investment of firm 2.

- Commitment to sustainability investment usually increases firms' profits in the industry, especially under commitment by all competing firms, implying that firms have the economic incentive to commit to sustainability investment. When both firms commit to sustainability investment, total profits in the industry may increase up to approximately $181 \%$, compared to those under no commitment.

- When only firm 1 commits to sustainability investment, such unilateral commitment may benefit firm 2 more than firm 1. Although firm 1 also benefits from its commitment compared to 
without commitment, firm 2 obtains relatively higher profit than the committed firm when the sustainability investment is relatively costly and/or when consumers have strong taste preferences. In such circumstances, firm 1's commitment to sustainability investment enables firm 2 to differentiate itself from firm 1 profitably.

- From the entire societal perspective, commitment by all competing firms is always the least desirable scenario, as it results in the lowest social welfare and the lowest sustainability investment in the industry. However, a unilateral commitment by a single firm may be more effective than the no commitment scenario, leading to the highest social welfare and the highest sustainability investment, when the sustainability investment is not too burdensome and when taste preferences of consumers are not too strong.

- Interestingly, the profit of each firm under competition increases when the sustainability investment becomes more costly because the heightened burden of sustainability investment mitigates competition in the sustainability dimension. Similarly, when consumers have stronger taste preferences, the two competing firms' profits increase because it becomes more costly for a firm to induce consumers closer to the competitor to choose a product of its own, which softens the competition between two firms.

The results in our study also provide important practical implications regarding the recent moves of firms to commit to sustainability strategies. As climate change becomes a more critical issue, some firms are announcing their investment plans for environmental initiatives in advance (e.g., Siemens, Walmart, L'Oréal, P\&G and H\&M). Our results show that these moves are rational in that committing to sustainability strategies provides a higher profit for the committed firm under competition. Firms' profits become the greatest when all competing firms join the initiative of committing to an environmental strategy.

However, despite firms' economic incentives toward commitment, commitment to sustainability investment can hurt the sustainability improvement in industries. That is, recent moves toward commitment may lessen firms' sustainability investment. Our results imply that, when some firms commit to sustainability investment while other firms do not, commitment may increase the committed firm's sustainability investment significantly, and hence the total sustainability investment in the industry. However, when all competing firms make the commitment, it no longer facilitates the sustainability investment of firms and instead serves as a means to mitigate competition in the industry, resulting in the lowest sustainability investment. Therefore, policymakers and NGOs should not give unconditional support to firms that commit to their sustainability investment on a long-term basis. In particular, when more firms start to commit to sustainability investment, whether the commitment is utilized to promote higher sustainability investment or whether it is used as a means to avoid competition in the sustainability dimension should be carefully monitored. Furthermore, when the commitment strategy becomes prevalent in the competitive industry, policymakers need to understand that commitment strategy can be jointly utilized by firms as a means to avoid costly competition in the sustainability dimension and consider more active intervention to incentivize the firm's sustainability investment, either through using penalties or devising subsidies mechanism.

In addition, the analysis result suggests that commitment by a single firm may result in the unanticipated result of making the competitor more profitable than the committed firm itself. When sustainability investment is relatively costly or consumers have relatively strong taste preferences, a profit increase of the committed firm remains relatively marginal. However, a profit increase of the competing firm that does not make a commitment can be more significant.

This study has several limitations. First, we consider a stylized model where two firms compete in the same market, each selling one product. However, in practice, multiple firms compete with each other and firms often sell diverse products at the same time. There can be also suppliers or retailers that each firm depends on. Incorporating these factors with regard to the effects of commitment under competition would be interesting future topics. Second, we consider the case where the market is 
fully covered in order to focus on the effects of commitment. Extending this study to the setting of incomplete market coverage would increase the generalizability of the insights.

Author Contributions: Both authors contributed to this study significantly.

Funding: This research received no external funding.

Conflicts of Interest: The authors declare no conflict of interest.

\section{Appendix A Proofs}

Proof of Theorem 2. (i) Differentiating $s_{1}^{S C *}$ with respect to $k$ yields $\frac{\partial s_{1}^{S C *}}{\partial k}=-\frac{64 d^{2}\left(13-576 d k+6912 d^{2} k^{2}\right)}{\left(1-128 d k+2304 d^{2} k^{2}\right)^{2}}$. Since $13-576 d k+6912 d^{2} k^{2}>0$ for all $d, k$, it holds that $\frac{\partial s_{1}^{S C *}}{\partial k}<0$. Differentiating $p_{1}^{S C *}$ with respect to $k$ yields $\frac{\partial p_{1}^{S C *}}{\partial k}=\frac{16 d^{2}\left(7-288 d k+2304 d^{2} k^{2}\right)}{\left(1-128 d k+2304 d^{2} k^{2}\right)^{2}}$, where $7-288 d k+2304 d^{2} k^{2}=0$ have two real roots, $d k=\frac{1}{48}(3-\sqrt{2})<\frac{2+\sqrt{31}}{144}, d k=\frac{1}{48}(3+\sqrt{2})>\frac{2+\sqrt{31}}{144}$. Therefore, $\frac{\partial p_{1}^{S C *}}{\partial k}>0$ if $d k>\frac{1}{48}(3+\sqrt{2})$ and $\frac{\partial p_{1}^{S C *}}{\partial k}<0$ otherwise. Similarly, differentiating $\pi_{1}^{S C *}$ with respect to $k$ yields $\frac{\partial \pi_{1}^{S C *}}{\partial k}=\frac{32 d^{2}(24 d k-1)(96 d k-5)}{\left(1-128 d k+2304 d^{2} k^{2}\right)^{2}}$, thus $\frac{\partial \pi_{1}^{S C *}}{\partial k}>0$.

(ii) Differentiating $s_{2}^{S C *}$ with respect to $k$ yields $\frac{\partial s_{2}^{S C *}}{\partial k}=-\frac{32 d^{2}\left(47-2016 d k+20,736 d^{2} k^{2}\right)}{\left(1-128 d k+2304 d^{2} k^{2}\right)^{2}}$, where the two roots of $47-2016 d k+20,736 d^{2} k^{2}=0$ are $d k=\frac{1}{144}(7+\sqrt{2})>\frac{7}{144}, d k=\frac{1}{144}(7-\sqrt{2})<\frac{7}{144}$. Thus, the result with regard to $\frac{\partial s_{2}^{S C *}}{\partial k}$ holds. Differentiating $p_{2}^{S C *}$ with respect to $k$ yields $\frac{\partial p_{2}^{S C *}}{\partial k}=$ $-\frac{16 d^{2}\left(7-288 d k+2304 d^{2} k^{2}\right)}{\left(1-128 d k+2304 d^{2} k^{2}\right)^{2}}=-\frac{\partial p_{1}^{S C *}}{\partial k}$, which proves the result with regard to $\frac{\partial p_{2}^{S C *}}{\partial k}$. In addition, $\frac{\partial \pi_{2}^{S C *}}{\partial k}=$ $\frac{4 d^{2}(48 x+1)(144 x-7)\left(7-320 x+3840 x^{2}\right)}{\left(1-128 d k+2304 d^{2} k^{2}\right)^{3}}>0$ holds.

(iii) Differentiating $s_{1}^{S C *}$ with respect to $d$ yields $\frac{\partial s_{1}^{S C *}}{\partial d}=-\frac{8\left(1-48 d k+768 d^{2} k^{2}\right)}{\left(1-128 d k+2304 d^{2} k^{2}\right)^{2}}>0$. Differentiating $p_{1}^{S C *}$ with respect to $d$ yields $\frac{\partial p_{1}^{S C *}}{\partial d}=\frac{2-288 d k+20,736 d^{2} k^{2}-589,824 d^{3} k^{3}+5,308,416 d^{4} k^{4}}{\left(1-128 d k+2304 d^{2} k^{2}\right)^{2}}$. Since the discriminant of the equation $2-288 d k+20,736 d^{2} k^{2}-589,824 d^{3} k^{3}+5,308,416 d^{4} k^{4}=0$ with respect to $d k$ is negative, there are two real roots of this equation, where the larger root is $d k=0.0578$ (i.e., $t_{1}^{S C}$ in Theorem 2), and the smaller root is $d k=0.0349$. Thus, the result with regard to $\frac{\partial p_{1}^{S C *}}{\partial d}$ is proved. Similarly, $\frac{\partial \pi_{1}^{S C *}}{\partial d}=\frac{2\left(1-96 d k+5568 d^{2} k^{2}-147,456 d^{3} k^{3}+1,327,104 d^{4} k^{4}\right)}{\left(1-128 d k+2304 d^{2} k^{2}\right)^{2}}$ and the discriminant of the equation $1-$ $96 d k+5568 d^{2} k^{2}-147,456 d^{3} k^{3}+1,327,104 d^{4} k^{4}=0$ with respect to $d k$ is negative. Thus, there are two real roots, where the larger root is $d k=0.0508$ and the smaller root is $d k=0.0416$, which proves the result with regard to $\frac{\partial \pi_{1}^{S C *}}{\partial d}$.

(iv) Differentiating $s_{2}^{S C *}$ with respect to $d$ yields $\frac{\partial S_{2}^{S C *}}{\partial d}=-\frac{2\left(7-288 d k+2304 d^{2} k^{2}\right)}{\left(1-128 d k+2304 d^{2} k^{2}\right)^{2}}$, thus it has the same sign as $\frac{\partial p_{2}^{S C *}}{\partial k}$. Since $-7+664 d k-18,432 d^{2} k^{2}+165,888 d^{3} k^{3}>0$ holds, it holds that $\frac{\partial p_{2}^{S C *}}{\partial d}=\frac{32 d k\left(-7+664 d k-18,432 d^{2} k^{2}+165,888 d^{3} k^{3}\right)}{\left(1-128 d k+2304 d^{2} k^{2}\right)^{2}}>0$. Finally, differentiating $\pi_{2}^{S C *}$ with respect to $d$ yields $\frac{\partial \pi_{2}^{S C *}}{\partial d}=\frac{8 d k(144 d k-7)\left(7-624 d k+28,160 d^{2} k^{2}-626,688 d^{3} k^{3}+5,308,416 d^{4} k^{4}\right)}{\left(1-128 d k+2304 d^{2} k^{2}\right)^{3}}$. Since $144 d k-7>0$ and $7-624 d k+28,160 d^{2} k^{2}-626,688 d^{3} k^{3}+5,308,416 d^{4} k^{4}>0$, it holds that $\frac{\partial \pi_{2}^{S C *}}{\partial d}>0$.

Proof of Theorem 4. (i) Comparing $s_{1}^{S C}$ and $s_{1}^{B C}, s_{1}^{S C}>s_{1}^{B C} \leftrightarrow \frac{8 d(24 d k-1)}{1-128 d k+2304 d^{2} k^{2}}>\frac{1}{12 k} \leftrightarrow 32 d k-1>0$ holds. Comparing $s_{1}^{S C}$ and $s_{1}^{N}, s_{1}^{A}>s_{1}^{N} \leftrightarrow \frac{8 d(24 d k-1)}{1-128 d k+2304 d^{2} k^{2}}>\frac{1}{8 k} \leftrightarrow-1+64 d k-768 d^{2} k^{2}>0 \leftrightarrow d k<$ $\frac{1}{16}$. Thus, $s_{1}^{S C}>s_{1}^{N}$ if $d k<\frac{1}{16}$ and $s_{1}^{S C}<s_{1}^{N}$ otherwise. It is straightforward that $s_{i}^{N}>s_{i}^{B C}$ holds. 
(ii) Comparing $s_{2}^{S C}$ and $s_{2}^{B C}, s_{2}^{S C}>s_{2}^{B C} \leftrightarrow \frac{2 d(144 d k-7)}{1-128 d k+2304 d 2 k 2}>\frac{1}{12 k} \leftrightarrow-1-40 d k+1152 d^{2} k^{2}>0$ holds. Similarly, $s_{2}^{S C}>s_{2}^{N} \leftrightarrow \frac{2 d(144 d k-7)}{1-128 d k+2304 d 2 k 2}>\frac{1}{8 k} \leftrightarrow 16 d k-1>0$. Thus, $s_{2}^{S C}>s_{2}^{N}$ if $d k>\frac{1}{16}$ and $s_{2}^{S C}<s_{2}^{N}$ otherwise.

(iii) Since $s_{1}^{S C}>s_{2}^{S C} \leftrightarrow 16 d k-1$, the result in (iii) is proved.

(iv) Since $\sum s_{i}^{S C}=\frac{2 d(240 d k-11)}{1-128 d k+2304 d^{2} k^{2}}, \sum s_{i}^{S C}>\sum s_{i}^{B C} \leftrightarrow \frac{2 d(240 d k-11)}{1-128 d k+2304 d^{2} k^{2}}>\frac{1}{6 k} \leftrightarrow-1-4 d k+576 d^{2} k^{2}>0$ holds. Comparing $\sum s_{i}^{S C}$ and $\sum s_{i}^{N}, \sum s_{i}^{S C}>\sum s_{i}^{N} \leftrightarrow \frac{2 d(240 d k-11)}{1-128 d k+2304 d^{2} k^{2}}>\frac{1}{4 k} \leftrightarrow 1-40 d k+384 d^{2} k^{2}<0 \leftrightarrow d k<\frac{1}{16}$. Thus, $\sum s_{i}^{S C}>\sum s_{i}^{N}$ if $d k<\frac{1}{16}$ and $\sum s_{i}^{S C}<\sum s_{i}^{N}$ otherwise.

Proof of Theorem 5. It is clear that $p_{1}^{S C}>p_{i}^{B C}=p_{i}^{N} \leftrightarrow \frac{2 d(24 d k-1)(48 d k-1)}{1-128 d k+2304 d^{2} k^{2}}>d \leftrightarrow 16 d k-1<0$ and $p_{2}^{S C}>p_{i}^{B C}=p_{i}^{N} \leftrightarrow \frac{16 d^{2} k(144 d k-7)}{1-128 d k+2304 d^{2} k^{2}}>d \leftrightarrow 16 d k-1>0$, which completes the proof.

Proof of Theorem 6. (i) Comparing $\pi_{1}^{S C}$ and $\pi_{1}^{B C}, \pi_{1}^{S C}<\pi_{1}^{B C} \leftrightarrow \frac{2 d(24 d k-1)^{2}}{1-128 d k+2304 d^{2} k^{2}}<\frac{72 d k-1}{144 k} \leftrightarrow 1+88 d k$ $-2304 d^{2} k^{2}<0$ holds. Furthermore, $\pi_{1}^{S C}>\pi_{1}^{N} \leftrightarrow \frac{2 d(24 d k-1)^{2}}{1-128 d k+2304 d^{2} k^{2}}>\frac{32 d k-1}{64 k} \leftrightarrow(16 d k-1)^{2}>0$. Comparing $\pi_{1}^{N}$ and $\pi_{1}^{B C}, \pi_{1}^{B C}>\pi_{1}^{N} \leftrightarrow \frac{72 d k-1}{144 k}>\frac{32 d k-1}{64 k} \leftrightarrow 40 k>0$.

(ii) Comparing $\pi_{2}^{S C}$ and $\pi_{2}^{B C}, \pi_{2}^{S C}<\pi_{2}^{B C} \leftrightarrow \frac{4 d^{2} k(144 d k-7)^{2}(32 d k-1)}{\left(1-128 d k+2304 d^{2} k^{2}\right)^{2}}<\frac{72 d k-1}{144 k} \leftrightarrow 1-328 d k$ $+11,200 d^{2} k^{2}-36,864 d^{3} k^{3}-1,327,104 d^{4} k^{4}<0 . \quad \mathrm{A}$ discriminant of the equation $1-328 d k+11,200 d^{2} k^{2}-36,864 d^{3} k^{3}-1,327,104 d^{4} k^{4}=0$ with respect to $d k$ is positive, and this equation has four real roots, where the numerical values are $d k=$ $-0.117, d k=0.003, d k=0.039, d k=0.047$. Thus, $\pi_{2}^{S C}<\pi_{2}^{B C}$ holds. Furthermore, $\pi_{2}^{S C}>\pi_{2}^{N} \leftrightarrow \frac{4 d^{2} k(144 d k-7)^{2}(32 d k-1)}{\left(1-128 d k+2304 d^{2} k^{2}\right)^{2}}>\frac{32 d k-1}{64 k} \leftrightarrow(16 d k-1)(32 d k-1)\left(1-240 d k+4608 d^{2} k^{2}\right)>0$.

Since $\left(1-240 d k+4608 d^{2} k^{2}\right)>0$ and $(32 d k-1)>0, \pi_{2}^{S C}>\pi_{2}^{N}$ if $d k>\frac{1}{16}$ and $\pi_{2}^{S C}<\pi_{2}^{N}$ otherwise.

(iii) Comparing $\pi_{1}^{S C}$ and $\pi_{2}^{S C}, \pi_{1}^{S C}>\pi_{2}^{S C} \leftrightarrow \frac{2 d(24 d k-1)^{2}}{1-128 d k+2304 d^{2} k^{2}}>\frac{4 d^{2} k(144 d k-7)^{2}(32 d k-1)}{\left(1-128 d k+2304 d^{2} k^{2}\right)^{2}} \leftrightarrow$ $-2(16 d k-1)\left(1-62 d k+864 d^{2} k^{2}\right)\left(1-128 d k+2304 d^{2} k^{2}\right)$. Since $\left(1-62 d k+864 d^{2} k^{2}\right)>0$ and $\left(1-128 d k+2304 d^{2} k^{2}\right)>0, \pi_{1}^{S C}>\pi_{2}^{S C}$ if $d k<\frac{1}{16}$ and $\pi_{1}^{S C}<\pi_{2}^{S C}$ otherwise.

(iv) Since $\sum \pi_{i}^{S C}=\frac{2 d\left(1-274 d k+16,192 d^{2} k^{2}-354,816 d^{3} k^{3}+2,654,208 d^{4} k^{4}\right)}{\left(1-128 d k+2304 d^{2} k^{2}\right)^{2}}$, $\sum \pi_{i}^{S C}<\sum \pi_{i}^{B C} \leftrightarrow 1-184 d k-32 d^{2} k^{2}+230,400 d^{3} k^{3}-3,317,760 d^{4} k^{4}<0$. The numerical values of the four real roots of $1-184 d k-32 d^{2} k^{2}+230,400 d^{3} k^{3}-3,317,760 d^{4} k^{4}=0$ with respect to $d k$ are $d k=-0.0263, d k=0.0056, d k=0.0428, d k=0.0473$. Thus, $\sum \pi_{i}^{S C}<\sum \pi_{i}^{B C}$ holds. Comparing $\sum \pi_{i}^{S C}$ and $\sum \pi_{i}^{N}, \sum \pi_{i}^{S C}>\sum \pi_{i}^{N} \leftrightarrow(16 d k-1)\left(-1+208 d k-8320 d^{2} k^{2}+92,160 d^{3} k^{3}\right)>0$. Since $\left(-1+208 d k-8320 d^{2} k^{2}+92,160 d^{3} k^{3}\right)>0$ holds, $\sum \pi_{i}^{S C}>\sum \pi_{i}^{N}$ if $d k>\frac{1}{16}$ and $\sum \pi_{i}^{S C}<\sum \pi_{i}^{N}$ otherwise. It is clear from Theorem $6(\mathrm{i})$ that $\sum \pi_{i}^{B C}>\sum \pi_{i}^{N}$ holds.

Proof of Theorem 7. It is straightforward that $\Delta s=2 / 3$. Furthermore, $\Delta \pi=\frac{2304 d k-32}{2304 d k-72}$, thus differentiating $\Delta \pi$ with respect to $k$ yields $\frac{\partial}{\partial k}(\Delta \pi)=-\frac{160 d}{9(32 d k-1)^{2}}<0$. Similarly, $\frac{\partial}{\partial d}(\Delta \pi)<0$. As $\Delta \pi$ decreases in $d k$, the maximum value of $\Delta \pi$ is attained at $d k=\frac{7}{144}$, which leads to $\Delta \pi=2 . \Delta \pi>1$ is clear from Theorem 6 .

Proof of Theorem 8. (i) Comparing $C S^{S C}$ and $C S^{B C}, C S^{S C}>C S^{B C} \leftrightarrow-4+592 d k-7936 d^{2} k^{2}-307$, $200 d^{3} k^{3}+5,308,416 d^{4} k^{4}>0$ holds. Comparing $C S^{S C}$ and $C S^{N C}$ yields: $C S^{S C}>C S^{N C} \leftrightarrow(16 d k-1)\left(-1+168 d k-5632 d^{2} k^{2}+55,296 d^{3} k^{3}\right)<0 \leftrightarrow d k<1 / 16 \quad$ because $-1+168 d k-5632 d^{2} k^{2}+55,296 d^{3} k^{3}>0$ holds. It is clear that $C S^{N}>C S^{B C}$ holds.

(ii) The equilibrium $S W^{i}=\sum \pi_{i}^{i}+C S^{i}$ are summarized as follows: $S W^{B C}=V-\frac{9 d k-1}{36 k}, S W^{S C}=$ $V-\frac{d\left(15-2256 d k+86,528 d^{2} k^{2}-1,216,512 d^{3} k^{3}+5,308,416 d^{4} k^{4}\right)}{4\left(1-128 d k+2304 d^{2} k^{2}\right)^{2}}$, and $S W^{N}=V-\frac{8 d k-1}{32 k}$. Then, comparing $S W^{S C}$ and $S W^{B C}, S W^{S C}>S W^{B C} \leftrightarrow-4+520 d k-11,968 d^{2} k^{2}+1,327,104 d^{4} k^{4}>0$ holds. Comparing $S W^{S C}$ 
and $S W^{N}, S W^{S C}>S W^{N} \leftrightarrow-4(16 d k-1)^{2}\left(1-112 d k+1152 d^{2} k^{2}\right)>0 \leftrightarrow d k<\frac{7+\sqrt{31}}{144}$. It is clear that $S W^{N}>S W^{B C}$.

\section{References}

1. Kim, T.-H.; Kim, B. Firm's Environmental Expenditure, R\&D Intensity, and Profitability. Available online: https:/ /www.mdpi.com/2071-1050/10/6/2071 (accessed on 8 April 2019).

2. Lee, S.-H.; Lee, S.-Y. An Analysis of the Effects of Climate Change Policy, Stakeholder Pressure, and Corporate Carbon Management on Carbon Efficiency on the Korean Petrochemical Industry. Available online: https:/ / www.mdpi.com/2071-1050/10/12/4420 (accessed on 8 April 2019).

3. Nielsen. The Sustainability Imperative: New Insights on Consumer Expectations. Available online: https:/ /www.nielsen.com/content/dam/nielsenglobal/dk/docs/global-sustainability-report-oct2015.pdf (accessed on 9 February 2019).

4. CDP. Global 500 Climate Change Report 2013. CDP Sector Insights: What is Driving Climate Change Action in the World's Largest Companies? Available online: https://www.pwc.es/es/publicaciones/gestionempresarial/assets/global-500-climate-change-report-2013.pdf (accessed on 9 February 2019).

5. Siemens. Siemens to Be Climate Neutral by 2030. Available online: https://www.siemens.com/press/ PR2015090345COEN (accessed on 9 February 2019).

6. Walmart. Walmart Commits to Reduce Emissions by 50 Million Metric Tons in China. Available online: https://news.walmart.com/2018/03/29/walmart-commits-to-reduce-emissions-by-50-millionmetric-tons-in-china (accessed on 9 February 2019).

7. P\&G. P\&G Announces New Environmental Sustainability Goals Focused on Enabling and Inspiring Positive Impact in the World. Available online: https: / /news.pg.com/press-release/pg-announces-newenvironmental-sustainability-goals-focused-enabling-and-inspiring-pos (accessed on 9 February 2019).

8. L'Oréal. L'Oréal Announces Its New Sustainability Commitment for 2020 "Sharing Beauty with All". Available online: http://www.loreal.ca/en-ca/media/press-releases/2013/oct/1\%E2\%80\%99or\% C3\%A9al-announces-its-new-sustainability-commitment-for-2020-sharing-beauty-with-all (accessed on 9 February 2019).

9. H\&M. H\&M Group Sustainability Report 2017. Available online: https://about.hm.com/content/dam/ hmgroup/groupsite/documents/masterlanguage/CSR/reports/2017\%20Sustainability\%20report/HM_ group_SustainabilityReport_2017_FullReport.pdf (accessed on 9 February 2019).

10. Bagwell, K. Commitment and observability in games. Games Econom. Behav. 1995, 8, 271-280. [CrossRef]

11. Maggi, G. The value of commitment with imperfect observability and private information. RAND J. Econ. 1999, 30, 555-574. [CrossRef]

12. Suzumura, K.; Suzumura, K. Competition, Commitment, and Welfare; Oxford University Press: Oxford, UK, 1995.

13. Chen, X.; Luo, Z.; Wang, X. Impact of efficiency, investment, and competition on low carbon manufacturing. J. Clean. Prod. 2017, 143, 388-400. [CrossRef]

14. Yalabik, B.; Fairchild, R.J. Customer, regulatory, and competitive pressure as drivers of environmental innovation. Int. J. Prod. Econ. 2011, 131, 519-527. [CrossRef]

15. Galbreth, M.R.; Ghosh, B. Competition and sustainability: The impact of consumer awareness. Decis. Sci. 2013, 44, 127-159. [CrossRef]

16. Clemenz, G. Eco-labeling and horizontal product differentiation. Environ. Resour. Econ. 2010, 45, 481-497. [CrossRef]

17. Gilbert, S.M.; Cvsa, V. Strategic commitment to price to stimulate downstream innovation in a supply chain. Eur. J. Oper. Res. 2003, 150, 617-639. [CrossRef]

18. Nasser, S.; Turcic, D. To commit or not to commit: Revisiting quantity vs. price competition in a differentiated industry. Manag. Sci. 2016, 62, 1719-1733. [CrossRef]

19. van Damme, E.; Hurkens, S. Endogenous Stackelberg leadership. Games Econ. Behav. 1999, 28, 105-129. [CrossRef]

20. Dong, G.; Zhong, D. Tacit collusion of pricing strategy game between regional ports: The case of Yangtze river economic belt. Sustainability 2019, 11, 365. [CrossRef] 
21. Ghosh, D.; Shah, J. A comparative analysis of greening policies across supply chain structures. Int. J. Prod. Econ. 2012, 135, 568-583. [CrossRef]

22. Ma, W.; Cheng, Z.; Xu, S. A Game Theoretic Approach for Improving Environmental and Economic Performance in a Dual-Channel Green Supply Chain. Available online: https:/ / www.mdpi.com/2071-1050/ 10/6/1918 (accessed on 8 April 2019).

23. Li, C. Sourcing for supplier effort and competition: Design of the supply base and pricing mechanism. Manag. Sci. 2013, 59, 1389-1406. [CrossRef]

24. Hong, Z.; Guo, X. Green product supply chain contracts considering environmental responsibilities. Omega 2019, 83, 155-166. [CrossRef]

25. Ghosh, D.; Shah, J. Supply chain under green sensitive consumer demand and cost sharing contract. Int. J. Prod. Econ. 2015, 164, 319-329. [CrossRef]

26. Caldieraro, F. The role of brand image and product characteristics on firms' entry and OEM decisions. Manag. Sci. 2016, 62, 3327-3350. [CrossRef]

27. Pun, H. Channel structure design for complementary products under a co-operative environment. Decis. Sci. 2013, 44, 785-796. [CrossRef]

28. Hotelling, H. Stability in competition. Econ. J. 1929, 39, 41-57. [CrossRef]

29. Martin, S. Advanced Industrial Economics; Blackwell: Oxford, UK, 1993.

30. Tirole, J. The Theory of Industrial Organization; MIT Press: Cambridge, MA, USA, 1988.

31. Desai, P.S. Quality segmentation in spatial markets: When does cannibalization affect product line design? Mark. Sci. 2001, 20, 265-283. [CrossRef]

32. Liu, Y.; Tyagi, R.V. The benefits of competitive upward channel decentralization. Manag. Sci. 2011, 57, 741-751. [CrossRef]

33. Tyagi, R.K. Technological advances, transaction costs, and consumer welfare. Mark. Sci. 2004, 23, 335-344. [CrossRef]

34. CIO. Why Are Customers Loyal to Apple and the iPhone? Available online: https://www.cio. com/article/3013559/apple-phone/why-are-customers-loyal-to-apple-and-the-iphone.html (accessed on 9 February 2019).

35. Krass, D.; Nedorezov, T.; Ovchinnikov, A. Environmental taxes and the choice of green technology. Prod. Oper. Manag. 2013, 22, 1035-1055. [CrossRef] 